\title{
KONSERVASI ENERGI SEKTOR BANGUNAN RUMAH SAKIT CEMPAKA PUTIH PERMATA SURABAYA
}

\author{
Arrad Ghani Safitra'), Mochammad Denis Arifin Pratama Putra ${ }^{2)}$ \\ ${ }^{1,2)}$ Program Studi Sistem Pembangkit Energi, Politeknik Elektronika Negeri Surabaya \\ Email: arradgs@pens.ac.id ${ }^{1)}$ \\ Indonesia
}

\begin{abstract}
ABSTRAK
Konservasi energi didefinisikan sebagai penggunaan energi dan sumber daya energi secara efisien dan rasional tanpa mengurangi penggunaan energi yang memang benar-benar diperlukan. Konservasi dilakukan pada salah satu rumah sakit di Surabaya yaitu Rumah Sakit Cempaka Putih, Kebon Agung, Surabaya. Konservasi energi difokuskan pada sistem pengkondisian udara dengan metode menghitung Cooling Load Temperature Difference (CLTD) dan Overall Thermal Transfer Value (OTTV) untuk mengetahui peluang penghematan energi. OTTV memiliki standar nilai yaitu $\leq 45 \mathrm{Watt} / \mathrm{m}^{2}$ yang ditentukan oleh SNI 03-6389-2000 sedangkan perhitungan beban pendinginan akan dibandingkan dengan kapasitas AC yang terpasang. Pengambilan data dilakukan menggunakan environment meter, digital distance meter, dan tang ampere untuk memperoleh data temperatur, kelembaban, dan dimensi setiap ruangan. Hasil perhitungan beban pendinginan dengan asumsi okupansi setiap ruangan maksimum maka gedung Rumah Sakit Cempaka Putih Permata termasuk tidak terjadi pemborosan ketika dibandingkan dengan kapasitas AC yang terpasang namun dari sisi kenyamanan dapat dikatakan kurang memenuhi kebutuhan. Hasil perhitungan OTTV gedung RSIA Cempaka Putih Permata sebesar 31,47 Watt $/ \mathrm{m}^{2}$ termasuk bangunan hemat energi. Rekomendasi yang dapat diterapkan adalah menambah jumlah AC agar memenuhi tingkat kenyamanan termal dan selanjutnya diikuti dengan retrofit fluida refrigeran dengan hidrokarbon guna untuk menurunkan konsumsi daya listrik sebesar 20\% dengan nominal $\operatorname{Rp} 2,936,614.19$.
\end{abstract}

Kata kunci: konservasi energi, beban pendinginan, OTTV, Rumah Sakit Cempaka Putih, pengkondisian udara

\section{ABSTRACT}

Energy conservation is defined as using energy and energy resources efficiently and rationally without reducing the necessary energy usage. It is happening at one of the hospitals in Surabaya, namely Cempaka Putih Hospital, Kebon Agung, Surabaya. Energy conservation is focused on the air conditioning system by calculating Cooling Load Temperature Difference (CLTD) and Overall Thermal Transfer Value (OTTV) to determine energysaving opportunities. OTTV has a standard value of $\leq 45 \mathrm{Watts} / \mathrm{m} 2$ determined by SNI 03-6389-2000 while the calculation of cooling loads will be compared with the installed AC capacity. The cooling load calculation assumes the maximum occupancy of each room of the building Cempaka Putih Permata Hospital, including no waste when compared to the installed AC capacity still, from the comfort, a side can be said to meet the needs. OTTV calculation result of building Cempaka Putih Permata Hospital with value 31,47 Watt/m2 including, energy-saving building. Recommendations that can be applied are increasing the number of air conditioners to meet thermal comfort level, then retrofit refrigerant fluids with hydrocarbons reduce electrical power consumption by $20 \%$ with a nominal value of Rp 2,936,614.19.

\section{Keywords: energy conservation, cooling load, OTTV, Cempaka Putih Hospital, air conditioning.}

\section{PENDAHULUAN}

Upaya penghematan energi salah satunya adalah audit dan konservasi energi yang biasa diterapkan pada rumah tangga, perkantoran, rumah sakit, dan industri. Konservasi energi dapat didefinisikan sebagai kegiatan pemanfaatan sumber energi secara efisien dan rasional tanpa mengurangi konsumsi energi yang benar-benar diperlukan serta dapat diterima dan tidak merugikan masyarakat dalam melakukan pekerjaan atau kegiatan (Ary Bachtiar, 2014).

Audit energi merupakan langkah awal dalam kegiatan konservasi energi. Konservasi energi didefinisikan sebagai penggunaan energi, sumber energi dan sumber daya energi secara efisien dan rasional tanpa mengurangi penggunaan energi yang memang benar-benar diperlukan dan tidak menurunkan fungsi energi itu sendiri secara teknis namum memiliki tingkat ekonomi yang serendahrendahnya, dapat diterima oleh masyarakat serta tidak pula mengganggu lingkungan. (Prasetyo, Hadi, 2008). Sehingga konservasi energi merupakan penekanan penggunaan energi tanpa mengurangi kenyamanan pengguna serta membuat tingkat ekonomi yang serendah-rendahnya. Pertama, dilakukan pengukuran tingkat pemakaian energi eksisting dari operasional rumah sakit dan kemudian menghitung nilai Intensitas Konsumsi Energi (IKE) 
yang kemudian dibandingkan dengan standar di Indonesia. dengan diketahuinya perbandingan IKE dengan standar maka disitu terletak potensi penghematan dan efiensi energi (Adiprama, 2012).

Rumah Sakit Cempaka Putih, Kebon Agung, Surabaya merupakan sebuah rumah sakit untuk ibu dan anak. Rumah sakit ini mempunyai ruangan yang cukup banyak untuk menampung pasien dari ibu-ibu serta anak-anak yang sakit maupun melahirkan. Kegiatan audit dan konservasi energi yang diterapkan pada rumah sakit ini tidak hanya bertujuan untuk melakukan penghematan energi saja akan tetapi juga bertujuan untuk menstandarkan kondisi ruangan sesuai dengan perhitungan beban pendinginan dan OTTV yang dilakukan. Batasan OTTV pada bangunan yaitu $\leq 45 \mathrm{Watt} / \mathrm{m}^{2}$. Dengan memberikan harga batas tertentu untuk OTTV maka besar beban eksternal dapat dibatasi sehingga menurunkan beban pendinginan (Loekita, 2006).

Berdasarkan uraian tersebut, untuk membantu pemerintah Indonesia dalam program untuk hemat energi sebesar-besarnya terutama dibidang energi listrik maka dilakukan konservasi pada bangunan Rumah Sakit Cempaka Putih, Kebon Agung, Surabaya yang bertujuan untuk menganalisis peluang penghematan energi dan memberikan rekomendasi investasi yang diperlukan sesuai standar pada bangunan Rumah Sakit.

\section{METODE PENELITIAN}

Metode yang dilakukan dalam penelitian ini adalah metode observasi yaitu melakukan pengamatan dan pengambilan data secara langsung di Rumah Sakit Cempaka Putih Surabaya untuk keperluan pengolahan, analisa data, dan pemberian rekomendasi.

\subsection{Peralatan Penunjang}

\subsubsection{Clamp on Meter (Tang Ampere)}

Alat untuk mengukur arus dan tegangan instalasi baik AC dan DC. Dengan membuka jepitan tang ampere yang kemudian diletakkan pada sekeliling kabel terisolasi maka dapat mengukur arus dan sedangakan untuk mengukur tegangan dengan cara menarik kabel yang kemudian memparalelkan kedua kutub. Spesifikasi: AC Clamp on Current Ranges 200, 1000A; DC Voltage Range 1000 V; AC Voltage Range 750Vac; Resistance full scale $20 \mathrm{~K}$ ohms; Overload protection $250 \mathrm{~V}$ rms ac.

\subsubsection{Digital Distance Meter}

Alat untuk mengukur panjang atau jarak dengan lebih praktis. Digital Distance Meter menggunakan sinar laser untuk menentukan panjang, luas, dan bahkan volume suatu ruangan.

Spesifikasi: Jangkauan pengukuran: 0.05 - 40 meter; Penyimpanan data sampai 30 data.

\subsubsection{Environment Meter}

Alat untuk mengukur kondisi lingkungan yang biasanya dikemas menjadi satu alat dengan berbagai sensor didalamnya. Lingkungan yang biasa diukur berupa Suhu (Temperature), Kelembaban (Humidity), Intensitas cahaya (Lux), Kebisingan (dB), dan Kecepatan angin $(\mathrm{m} / \mathrm{s})$. Spesifikasi: Light (LUX) Range 2000x10 lux; Temperature Range $20^{\circ} \mathrm{C} \sim 750^{\circ} \mathrm{C}$; Humidity Range $35 \% \mathrm{RH} \sim 95 \%$; Sound Level Range $35 \mathrm{~dB} \sim 100 \mathrm{~dB}$.

\subsection{Pengambilan Data}

Kegiatan audit energi awal meliputi pengumpulan dan penyisipan data energi bangunan gedung dengan data yang tersedia dari pihak rumah sakit dan tidak memerlukan pengukuran seperti denah gedung, denah instalasi pencahayaan, single line diagram, dan tagihan pembayaran (listrik, gas, dan air) selama 5 tahun terakhir. Analisa distribusi penggunaan energi listrik pada gedung rumah sakit cempaka putih surabaya. Serta menghitung besarnya Intensitas Konsumsi Energi (IKE) selama 5 tahun sebelumnya berdasarkan data-data rincian luas bangunan gedung dan luas total bangunan gedung $\left(\mathrm{m}^{2}\right)$, kemudian konsumsi energi bangunan gedung per tahun ( $\mathrm{kWh} /$ tahun), serta biaya energi bangunan gedung $(\mathrm{Rp} / \mathrm{kWh})$.

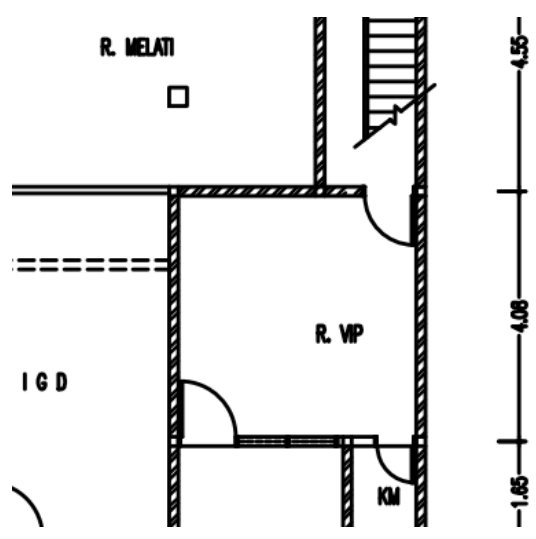

Gambar 1. Denah Ruang VIP

Audit energi rinci dilakukan apabila audit energi awal memberikan gambaran nilai IKE lebih tinggi dari standar. Audit rinci dimana pada tahapan ini dituntut untuk menganalisis peluang penghematan energi dari data hasil pengukuran langsung (data primer) dalam bentuk saran-saran yang dapat diterapkan kedepannya. Intensitas Konsumsi Energi (IKE) Listrik merupakan pembagian antara konsumsi energi listrik pada kurun waktu tertentu dengan satuan luas bangunan gedung. Dalam istilah lain, IKE listrik merupakan istilah yang digunakan untuk menyatakan besarnya pemakaian energi dalam bangunan gedung dan telah diterapkan di berbagai negara (ASEAN, APEC), dinyatakan dalam suatu $\mathrm{kWh} / \mathrm{m}^{2}$ per tahun (Sukisno, 2014). Sebagai pedoman, telah ditetapkan nilai standar IKE untuk bangunan di Indonesia yang telah ditetapkan oleh Depatemen Pendidikan Nasional Republik Indonesia tahun 2004 (Dewi, Resti, 2011). 


\section{HASIL DAN PEMBAHASAN}

Mengacu pada tujuan yang sudah dijelaskan di pendahuluan yaitu untuk menganalisis peluang penghematan energi dan memberikan rekomendasi investasi yang diperlukan sesuai standar pada bangunan Rumah Sakit, diperoleh hasil pada penelitian ini sebagai berikut.

\subsection{Beban Pendinginan (cooling load)}

Analisa beban pendinginan digunakan untuk mengetahui kebutuhan konsumsi energi dalam upaya mengkondisikan udara setiap ruangan pada bangunan Rumah Sakit Cempaka Putih Permata.

Tabel 1. Keterangan tabel Mid Alignment 8pt ditulis dengan huruf besar di awal saja demikian juga dengan judul-judul dalam tabel

\begin{tabular}{|c|c|c|c|c|c|}
\hline Nama ruangan & Q Total & $\begin{array}{c}\text { Jumlah } \\
\text { AC (PK) }\end{array}$ & $\begin{array}{l}\text { Q Total } \\
\text { (PK) }\end{array}$ & $\begin{array}{c}\text { AC req } \\
(\mathrm{PK})\end{array}$ & Keterangan \\
\hline R. IGD & 10490.4153 & 0 & 1.1656 & -1.1656 & Kurang 1 PK \\
\hline R. VIP & 5559.7400 & 0.5 & 0.6177 & -0.1177 & Sesuai \\
\hline R. Melati & 19143.1718 & 0 & 2.1270 & -2.1270 & Kurang 2 PK \\
\hline R. Apotik & 5034.4883 & 0.5 & 0.5594 & -0.0594 & Sesuai \\
\hline R. Rekam Medis & 3647.9885 & 0 & 0.4053 & -0.4053 & Kurang 0.5 PK \\
\hline R. Kantor & 4048.7902 & 0.5 & 0.4499 & 0.0501 & Sesuai \\
\hline R. Bersalin & 8346.3202 & 1 & 0.9274 & 0.0726 & Sesuai \\
\hline R. BKIA & 4883.9302 & 0 & 0.5427 & -0.5427 & Kurang 0.5 PK \\
\hline R. Bayi & 4105.2446 & 0.5 & 0.4561 & 0.0439 & Sesuai \\
\hline R. Rawat Kls II & 4876.5858 & 0.5 & 0.5418 & -0.0418 & Sesuai \\
\hline R. Rawat Kls II & 4876.5858 & 0.5 & 0.5418 & -0.0418 & Sesuai \\
\hline R. Rawat Kls II & 4876.5858 & 0.5 & 0.5418 & -0.0418 & Sesuai \\
\hline R. Rawat Kls II & 4825.5858 & 0.5 & 0.5362 & -0.0362 & Sesuai \\
\hline R. Poli & 4145.8031 & 0.5 & 0.4606 & 0.0394 & Sesuai \\
\hline R. Laboratorium & 3171.3291 & 0.5 & 0.3524 & 0.1476 & Sesuai \\
\hline \multicolumn{6}{|l|}{ R. Poli Anak } \\
\hline R. Poli Bedah & 4543.3840 & 0 & 0.5048 & -0.5048 & Kurang 0.5 PK \\
\hline \multicolumn{6}{|l|}{ R. Poli Penyakit Dalam } \\
\hline R. Rawat Kls III & 7471.6906 & 0 & 0.8302 & -0.8302 & Kurang 3/4 PK \\
\hline R. Rawat Kls III & 7212.2325 & 0 & 0.8014 & -0.8014 & Kurang 3/4 PK \\
\hline R. Rawat Kls III & 7198.7194 & 0 & 0.7999 & -0.7999 & Kurang 3/4 PK \\
\hline R. Poli Gigi & 4150.6162 & 0.5 & 0.4612 & 0.0388 & Sesuai \\
\hline R. Neonatus & 2941.0875 & 0.5 & 0.3268 & 0.1732 & Kurang 2 PK \\
\hline R. PreOp & 8734.2996 & 1.5 & 0.9705 & 0.5295 & Lebih 0.5 PK \\
\hline R. Operasi Kecil & 7626.9736 & 0 & 0.8474 & -0.8474 & Kurang 3/4 PK \\
\hline R. Sadar & 7087.0823 & 0 & 0.7875 & -0.7875 & Kurang 3/4 PK \\
\hline R. Dokter & 3413.1879 & 0.5 & 0.3792 & 0.1208 & Kurang 1 PK \\
\hline R. Operasi II & 6962.6968 & 0.5 & 0.7736 & -0.2736 & Kurang 0.5 PK \\
\hline R. Alat Steril & 4969.2181 & 0.5 & 0.5521 & -0.0521 & Sesuai \\
\hline R. Operasi I & 6833.5258 & 0.5 & 0.7593 & -0.2593 & Kurang 0.5 PK \\
\hline R. Jenazah & 5936.7454 & 0 & 0.6596 & -0.6596 & Kurang $0.5 \mathrm{PK}$ \\
\hline R. Genset & 2015.7560 & 0 & 0.2240 & -0.2240 & Kurang 0.5 PK \\
\hline R. Limen & 3921.8555 & 0 & 0.4358 & -0.4358 & Kurang $0.5 \mathrm{PK}$ \\
\hline R. Dapur & 7530.3234 & 0 & 0.8367 & -0.8367 & Kurang 3/4 PK \\
\hline R. Gizi & 3557.2771 & 0 & 0.3953 & -0.3953 & Kurang 1 PK \\
\hline R. Loundry & 3858.6107 & 0 & 0.4287 & -0.4287 & Kurang 0.5 PK \\
\hline R. Gudang & 2857.1201 & 0 & 0.3175 & -0.3175 & Kurang 0.5 PK \\
\hline R. Tunggu & 29846.9646 & 0 & 3.3163 & -3.3163 & Kurang 3.25 PK \\
\hline
\end{tabular}




\begin{tabular}{llllll} 
R. Front Office & 16320.3457 & 0 & 1.8134 & -1.8134 & Kurang 2 PK \\
\hline
\end{tabular}

Tabel 2. Beban Pendinginan Lantai 2 RSIA Cempaka Putih Permata

\begin{tabular}{llllll}
\hline \multicolumn{1}{c}{ Nama ruangan } & Q Total & $\begin{array}{c}\text { Jumlah } \\
\text { AC (PK) }\end{array}$ & $\begin{array}{c}\text { Q Total } \\
\text { (PK) }\end{array}$ & $\begin{array}{c}\text { AC req } \\
\text { (PK) }\end{array}$ & Keterangan \\
\hline R. Rekam Medik & 10624.3044 & 0 & 1.1805 & -1.1805 & Kurang 1 PK \\
R. Rapat Kecil & 10170.3280 & 0 & 1.1300 & -1.1300 & Kurang 1 PK \\
R. Pantry & 5464.8189 & 0.5 & 0.6072 & -0.1072 & Sesuai \\
R. Rapat Besar & 31202.7712 & 0 & 3.4670 & -3.4670 & Kurang 3.5 PK \\
R. Gudang & 4672.0242 & 0 & 0.5191 & -0.5191 & Kurang 0.5 PK \\
R. Asrama Karyawati I & 5328.1884 & 0 & 0.5920 & -0.5920 & Kurang 0.5 PK \\
R. Asrama Karyawati II & 5412.8480 & 0 & 0.6014 & -0.6014 & Kurang 0.5 PK \\
R. Asrama Karyawati III & 5412.8480 & 0 & 0.6014 & -0.6014 & Kurang 0.5 PK \\
\hline
\end{tabular}

Tabel 1 dan Tabel 2 menunjukkan hasil perhitungan beban pendinginan eksternal dan internal untuk setiap ruangan. Perhitungan total beban pendinginan kemudian dibandingkan dengan kapasitas AC yang terpasang pada setiap ruangan.

Pada lantai 1, ruang tunggu memiliki total beban pendinginan yang tertinggi yaitu 29846,96 Btu/hr dan tanpa pemasangan AC sehingga memiliki kekurangan kapasitas AC sebesar 3,25 PK. Perhitungan dilakukan dengan asumsi okupansi maksimum untuk setiap ruangan sehingga ruang tunggu dengan asumsi kapasitas okupansi sebanyak \pm 20 orang membuat total beban pendinginan menjadi tinggi. Ruang gudang memiliki total beban pendinginan terendah yaitu $2857,12 \mathrm{Btu} / \mathrm{hr}$ dan tanpa pemasangan $\mathrm{AC}$ sehingga memiliki kekurangan kapasitas AC sebesar 0.5 PK. Pada lantai 2, ruang rapat besar memiliki total beban pendinginan yang tertinggi yaitu $31202.77 \mathrm{Btu} / \mathrm{hr}$ dan tanpa pemasangan AC sehingga memiliki kekurangan kapasitas AC sebesar 3,5 PK. Nilai total beban pendinginan yang tinggi ini juga disebabkan oleh asumsi okupansi maksimum.

Pada kedua lantai keterangan menunjukkan tidak adanya pemborosan pemakaian energi untuk AC dikarenakan hampir semua ruangan mempunyai kapasitas AC yang kurang dan sisanya adalah pemasangan $\mathrm{AC}$ yang sesuai dengan total beban pendinginan. Meskipun termasuk tidak terjadinya pemborosan untuk gedung RSIA Cempaka Putih Permata namun kekurangan pendinginan ini dapat menyebabkan menurunnya tingkat kenyamanan penggunaan ruangan tersebut. Oleh karena itu disarankan agar kapasitas AC yang terpasang pada setiap ruangan ditambahkan untuk segi kenyamanan.

\subsection{Overall Thermal Transfer Value (OTTV)}

Analisa OTTV digunakan untuk mengetahui energi yang masuk kedalam bangunan yang dianalisa dari segi selubung tiap orientasi bangunan Rumah Sakit Cempaka Putih Permata. Parameter penting pada OTTV yaitu WWR yang merupakan rasio jendela terhadap dinding (Edward, G Pita, 2008).

Tabel 3. OTTV setiap orientasi RSIA Cempaka Putih Permata

\begin{tabular}{cccccccccc}
\hline Orientasi & $\alpha$ & Uw & WWR & Tdek & SC & SF & Uf & $\Delta$ T & OTTV \\
\hline Utara & 0.89 & 3.0728 & 0.0119 & 10 & 0.6236 & 130 & 5.8928 & 5 & 28.3353 \\
Selatan & 0.89 & 2.0831 & 0.0023 & 10 & 0.6025 & 97 & 5.8928 & 5 & 18.6972 \\
Timur & 0.89 & 3.0728 & 0.4594 & 10 & 0.6395 & 112 & 5.8928 & 5 & 61.2266 \\
Barat & 0.89 & 3.0728 & 0.0622 & 10 & 0.6395 & 243 & 5.8928 & 5 & 37.1498 \\
\hline
\end{tabular}

$$
\begin{aligned}
\text { OTTV } & =\frac{\sum A \times \text { OTTV }_{i}}{\sum A} \\
\text { OTTV } & =\frac{(237,41 \times 28,33)+(225,54 \times 18,69)+(103,35 \times 61,22)+(96,41 \times 37,15)}{(237,41+225,54+103,35+96,41)} \\
& =31,4672 \mathrm{Watt} / \mathrm{m}^{2}
\end{aligned}
$$

Perhitungan di atas menunjukkan hasil perhitungan OTTV untuk seluruh bangunan RSIA Cempaka Putih Permata. Berdasarkan perhitungan OTTV maka bangunan RSIA Cempaka Putih Permata termasuk bangunan hemat energi dengan nilai OTTV keseluruhan sebesar $31.47 \mathrm{Watt} / \mathrm{m}^{2}\left(<45 \mathrm{Watt} / \mathrm{m}^{2}\right)$. 


\subsection{Rekomendasi}

\subsubsection{Penambahan kapasitas AC}

Kondisi bangunan pada RSIA Cempaka Putih Permata dapat dikatakan memiliki konsumsi energi yang termasuk bangunan hemat energi namun kekurangan peralatan pendinginan sehingga dapat menyebabkan menurunkan tingkat kenyamanan penggunaan ruangan tersebut. Oleh karena itu disarankan agar kapasitas AC yang terpasang pada setiap ruangan ditambahkan agar kenyamanan termal tercapai. Berikut ini adalah rincian perhitungan penambahan kapasitas AC dengan fluida refrigerant R-22 untuk beberapa ruangan yang ditampilkan pada Tabel 4.

Tabel 4. Rincian penambahan kapasitas AC

\begin{tabular}{ccr}
\hline Jumlah & Kapasitas (PK) & \multicolumn{1}{c}{ Total Wh } \\
\hline 27 & $1 / 2$ & 2268000 \\
7 & $3 / 4$ & 890400 \\
7 & 1 & 1108000 \\
1 & 1,5 & 280800 \\
2 & 2 & 921600 \\
3 & 2,5 & 1850400 \\
2 & $1 / 2$ & 504000 \\
\hline \multicolumn{2}{c}{ Jumlah per bulan } & 7823200 \\
\hline
\end{tabular}

Jumlah pemakaian per bulan adalah $7823200 / 1000=7823 \mathrm{kWh}$. Setelah menerapkan penambahan kapasitas AC dengan asumsi okupansi maksimum untuk setiap ruangan maka konsumsi daya total dengan penerapan penambahan $\mathrm{AC}$ adalah $7823 \mathrm{kWh}$ di tambah dengan pemakaian bulanan sebelum adapenambahan AC sebesar $2184 \mathrm{kWh}$ sehingga total pemakaian per bulan menjadi 10007 kWh. Dari total daya yang digunakan kemudian menghitung nilai IKE agar diketahui kategori pemakaian energi setelah ditambahkan AC.

$$
\begin{aligned}
I K E & =\frac{\text { konsumsi daya }}{\text { luas }}=\frac{10007}{635,33} \\
& =15.75 \mathrm{kWh} / \mathrm{m}^{2}
\end{aligned}
$$

Nilai IKE sebesar $15.75 \mathrm{kWh} / \mathrm{m}^{2}$ termasuk dalam kriteria agak boros untuk ruangan ber-AC.

\subsubsection{Penggantian pendingin menjadi $\mathrm{MC}-22$}

Pada perhitungan penambahan kapasitas AC dengan fluida refrigerant R-22 termasuk dalam kriteria agak boros. Untuk mengatasi hal tersebut maka dapat diterapkan penggantian fluida pendingin menjadi Musicool-22 atau yang lebih dikenal dengan MC-22. Pada penelitian sebelumnya pendingin MC22 dapat menghemat penggunaan energi sebesar 20\% karena termasuk dalam golongan hidrokarbon (Widyastuti, 2014). Dengan pemakaian total setelah penambahan AC yaitu $10007 \mathrm{kWh}$ maka dengan penerapan retrofit refrigerant R-22 ke Musicool-22 akan menghemat sebesar $20 \%$ daya total sebesar 2001,4 kWh sehingga daya total menjadi 8005,6.
Perhitungan keuntungan penghematan dalam rupiah dengan nilai tarif listrik bulan April 2020 adalah 1467,28 Rp/kWh. Penghematan biaya = Rp 1467,28 x 2001,4 kWh $=\operatorname{Rp} 2,936,614.19$. Konsumsi daya untuk penerapan penggantian pendingin $\mathrm{MC}-22$ adalah 8968,2 kWh kemudian menghitung nilai IKE.

$$
I K E=\frac{\text { konsumsi daya }}{\text { luas }}=\frac{8005,6}{635,33}=
$$$$
12,6 \mathrm{kWh} / \mathrm{m}^{2}
$$

Nilai IKE sebesar $12,6 \mathrm{kWh} / \mathrm{m}^{2}$ termasuk dalam kriteria cukup efisien.

\section{KESIMPULAN}

Berdasarkan hasil penelitian yang telah dilakukan dan analisis maka dapat ditarik kesimpulan bahwa proses audit dan konservasi energi telah dilaksanakan pada keseluruhan bangunan RSIA Cempaka Putih Permata. Menurut hasil perhitungan pendekatan beban pendinginan dengan asumsi okupansi setiap ruangan maksimum dan menurut hasil perhitungan OTTV gedung RSIA Cempaka Putih Permata dengan nilai OTTV sebesar 31,47 Watt $/ \mathrm{m}^{2}$ termasuk bangunan hemat energi karena nilainya $<45 \mathrm{Watt} / \mathrm{m}^{2}$ serta termasuk tidak terjadi pemborosan ketika dibandingkan dengan kapasitas AC yang terpasang namun dari sisi kenyamanan dapat dikatakan kurang memenuhi kebutuhan. Rekomendasi yang dapat diterapkan yaitu melakukan penambahan kapasitas AC supaya tercapai kenyamanan termal yang dibutuhkan dan selanjutnya dikuiti penerapan retrofit fluida kerja refrigerant dari R-22 ke MC-22 guna untuk menekan konsumsi daya listrik per bulan sebesar $20 \%$ dengan nominal Rp 2,936,614.19.

\section{UCAPAN TERIMA KASIH}

Terima kasih kepada RSIA Cempaka Putih Surabaya sebagai tempat Penulis melakukan penelitian yang sangat ramah dan siap membantu segala proses baik pengambilan data dan juga konsultasi dengan teknisi.

\section{DAFTAR PUSTAKA}

Adiprama, T. R. \& Ciptomulyono, U. 2012. Audit Energi dengan Pendekatan Metode MCDMPROMETHEE untuk Konservasi serta Efisiensi Listrik di Rumah Sakit Haji Surabaya. Surabaya : Institut Teknologi Sepuluh November.

Dewi, R. P., Sarwono, \& Hantoro, R. 2011. Audit Dan Konservasi Energi Pada Rumah Sakit Angkatan Laut DR. Ramelan Surabaya. Surbaya : Department of Engineering Physics, Faculty of Industrial Technology ITS Surabaya Indonesia.

Dimas, T. A., Fitria, D., \& Junus, T. D. Perbandingan Perhitungan OTTV dan ETTV Gedung Komersial - Kantor. Green Building 
Engineers, Divisi Sustainability, PT Asdi Swasatya.

Edward G. Pita. Air Conditioning Principles and Systems. Fourth Editon. Environmental Control Technology New York City Technical Collage The City University of New York.

Loekita, S. 2006. ANALISIS KONSERVASI ENERGI MELALUI SELUBUNG BANGUNAN. Surabaya : Jurusan Teknik Sipil, Universitas Kristen Petra.

Prasetio, H. 2008. KONSERVASI ENERGI LISTRIK PADA INDUSTRI OTOMOTIF. Depok : Fakultas Teknik Program Studi Teknik Elektro.

Putra. A. B. K., dkk. 2014. Konservasi Energi Sektor Bangunan di Lingkungan Kampus ITS Surabaya sebagai Salah Satu Pengurangan
Emisi Karbon dalam Program ECO Campus. Surabaya : Institut Teknologi Sepuluh November.

Sukisno, Toto, Yuniarti, N., \& Sunyoto. 2014. TINGKAT INTENSITAS KONSUMSI ENERGI LISTRIK DI JURUSAN PENDIDIKAN TEKNIK ELEKTRO FT UNY: SEBUAH UPAYA MENUJU ISO 50001. Yogyakarta : Jurusan Pendidikan Teknik Elektro Fakultas Universitas Negeri Yogyakarta.

Widyastuti, dkk. 2014. Improved Energy Saving for R22 Building Air Conditioning Retrofitted with Hydrocarbon Refrigerant, Study Case : Civil Engineering Department of ITS. Surabaya : Department of Material and Metallurgical Engineering, Sepuluh Nopember Institute of Thecnology Surabaya. 